\title{
Cell based therapies in neurological diseases
}

\author{
Adriana Dulămea
}

Corresponding author: Adriana Dulamea Department of Neurology, Fundeni Clinical Institute e-mail: adrianadul@yahoo.com
"Carol Davila" University of Medicine and Pharmacy, Bucharest, Romania

Department of Neurology, Fundeni Clinical Institute, Bucharest, Romania

\section{ABSTRACT}

Cell therapy is a field witch has undergone tremendous expansion in recent years. A search in PubMed of the research studies on this particular subject shows an increase of up to 30,000 per year, over the past 12 years. Cell therapy is based on the idea that exogenous administration of stem cells will provide protection of the partially damaged cells and stimulate the endogenous mechanisms of tissue repair. The author presents data about characterization of stem cells, mechanisms of action and special features of mesenchymal stem cells.

Key words: mesenchimal stem cells, neuroprotection, neuroregeneration

\section{INTRODUCTION}

Translational Medicine is a new, emerging approach to the practice of medicine and to interventional epidemiology, integrating the information from fundamental research studies, as well as from social and political sciences, in order to optimize therapy and disease prevention methods. The process aims at transforming the discoveries made through groundbreaking research into drug therapies or medical tools. This new medical field makes the connection among experimental studies, clinical trials and clinical practice.

Generally, in adult pathological conditions that involve cell destruction or inflammation, adult stem cells, which are present latently throughout life, are stimulated to multiply, differentiate and migrate to the damaged tissue or organ, where they secrete trophic, anti-inflammatory factors or factors involved in immunomodulation and immunosuppression and where they can even differentiate into cells of the damaged tissue.

However, the intervention of stem cells is insufficient to stop pathological processes and to trigger the regeneration of the damaged tissues. For this reason, researchers have attempted to develop, on animal models of various diseases, regenerative cell therapies based on the external input of stem cells or of cells derived therefrom, that complement and stimulate the body's natural response. 
There are numerous ongoing clinical studies conducted for the purpose of evaluating the safety and efficiency of therapies using adult stem cells, particularly stem cells from hematogenous bone marrow and mesenchymal stem cells from adipose tissue, embryonic stem cells, fetal and umbilical cord cells, for a wide variety of pathological processes specific to neurodegenerative, autoimmune, genetic diseases, in traumatic brain or spinal injuries, for neural regeneration after stroke, as delivery vectors for gene therapy in invasive brain tumors in idiopathic epilepsies, as well as in muscle diseases and peripheral neuropathies.

\section{Characterization of stem cells}

Stem cells are different from other precursor cells by two specific features. Firstly, they are self-renewing, possessing the capacity to proliferate and to reproduce indefinitely. Secondly, they are multi- or pluripotent, meaning that they are able to differentiate into multiple cell types. These processes are regulated by the microenvironment in which they live.

\section{Cell therapy in neurological diseases}

There are already numerous preclinical studies on experimental models of neurological pathology and clinical trials, either ongoing or completed, which have revealed the features and action mechanisms of different types of stem cell populations in immunomodulation, the induced neuroprotection and neurogenesis, thus showing the capabilities of these cells in neuroregeneration and neuroplasticity.

The stem cell populations used in neurological diseases were very diverse. Embryonic stem cells (ESC) which represent the stem cell prototype have an extremely high capacity to transdifferentiate 1$]$, but their transplantation is associated with a high risk of carcinogenesis 2]. The somatic stem cells used in the process were neural stem cells (NSC) 3. a $n \quad d$ mesenchymal stem cells (MSC) 4 which are relatively easy to harvest from different adult tissues and can be expanded in vitro. NSC-s have the advantage of being naturally "neuralized", but involve many scientific, legal and ethical limitations regarding their harvesting and transplantation into an adult brain 5]. Another disadvantage is that after extended culture they tend to assume a glial cell pattern that diminishes their therapeutic potential.

Mesenchymal stem cells (MSC) are a heterogeneous population of stromal cells isolated from hematogenous bone marrow and tissues derived from mesoderm: adipose tissue, pleural cavity, spleen, thymus, peritoneal cavity, lymph node, muscle, teeth.

In 2006, the International Society for Cellular Therapy (ISCT) proposed minimum criteria to define human MSC 6]:

(1) MSCs must be adherent to plastic when maintained in standard culture conditions;

(2) MSCs must express CD105, CD73 and CD90 and they must lack expression of CD34, CD45, CD14 or CD11b, CD79a, CD19 and HLADR surface molecules;

(3) MSCs must differentiate in vitro into osteoblasts, chondroblasts and adipocytes

MSCs from the bone marrow (BM) or BM nonhematopoietic stem cells contribute to the formation of hematopoietic stem cells (HSC) niche that support hematopoiesis $7 . \quad$ and maintain HSCs in a quiescent state exhibiting an anti-proliferative activity 8,9]

Within the bone marrow, MSCs are rare (approximately 1 in 10,000 cells) and can be isolated from other BM cells by their potency to adhere to tissue culture plastic; these cells have a spindle-shaped fibroblast- like morphology and can be expanded and enriched through culturing for 3-5 weeks 10, 11].

MSCs have many advantages: they are easy to harvest, can be quickly isolated, expanded and stored for a period of time, can be administered in various ways, are relatively immune-privileged and do not require immunosuppression even with allogeneic transplantation, they may be administered through different methods, have similar efficiency as neural stem cells, a good safety profile and do not raise ethical controversy.

\section{The mechanism of action and features of $\mathrm{MSC}$}

MSC show therapeutic potential for neurological and central nervous system lesions due to their mechanism of action and their unique properties: immunomodulation capacity, neuroprotection, neuroregeneration and neurogenesis 12]. If administered intravenously MSC migrate into lymphoid peripheral organs, which induces peripheral tolerance to $T$ cells by modulating the innate and adaptive immunity because their action on B, T and NK cells 13-17]. Most MSC are captured in the lungs where they induce regulation through cytokines involved in suppressing the inflammation, possibly by interacting with local cells such as macrophages. Numerous in vitro studies have shown that MSC migrate and cross the blood-brain lesions, being attracted to the central nervous system (CNS), a phenomenon called "homing" 18-20].

This mechanism is mediated especially by inflammatory chemokines concentrated at the site of inflamma- 
tion. At the CNS level, MSC interact and alter parenchymal brain cells through direct intercellular communication and/or indirect secretion of factors that can regulate axonal growth by exosome-mediated transfer of miR-133b to neuronal cells, thus triggering the functional recovery 21]. The main mechanism by which MSC operate is the secretion of a large variety of bio-active molecules such as growth factors, cytokines and chemokines through which they influence the neural precursors in the brain germinal niches, as well as the oligodendrocyte precursor cells, astrocytes and microglia.

\section{Effect on innate immunity}

MSCs have been shown to inhibit the maturation of monocytes, and cord-blood and CD34+ hematopoietic progenitor cells into myeloid dendritic cells (DCs) in vitro 22-25]. Furthermore, mature DCs incubated with MSCs have decreased cell-surface expression of MHC class II molecules, CD11c, CD83 and co-stimulatory molecules, as well as decreased interleukin-12 (II-12) production, thereby impairing the antigen-presenting function of the DCs 26-28]. MSCs can also decrease the pro-inflammatory potential of DCs by inhibiting their production of tumour-necrosis factor (TNFO 26]. Furthermore, plasmacytoid DCs (pDCs), which are specialized cells for the production of high levels of type I IFN in response to microbial stimuli, upregulate production of the anti-inflammatory cytokine II-10 after incubation with MSCs 26].

Other findings support the possibility that, following encounter with MSCs in vivo, activated NK cells could undergo limited functional inhibition that does not compromise their ability to kill MSCs 29].

\section{Effect on adaptive immunity}

MSCs can modulate the intensity of an immune response by inhibiting antigen-specific T-cell proliferation and cytotoxicity and promoting the generation of regulatory T cells. Most published studies indicate that MSCs inhibit B-cells proliferation in vitro 30-32. and they also can inhibit B-cell differentiation and the expression of chemokine receptors 32]. Other studies on animal models of experimental autoimmune encephalomyelitis (EAE) showed that MSCs have significant immunomodulating properties 33-38]. Gerdoni and his coworkers showed that the infusion of MSCs inhibit the production of antigen-specific antibodies and also downregulate the specific T-cell responses 32].

In 2005 Zappia and coworkers demonstrated that the intravenous (IV) injection of syngeneic
MSCs ameliorated the clinical course of Myelin Oligodendrocyte Glycoprotein (MOG)-induced EAE and reduced demyelination and leukocytes infiltration of the CNS 33].

The cells exerted these effects only when they were injected at onset or at the peak of the disease; administration during the chronic phase had no effect. One of the critical observations was that T cells isolated from treated mice did not proliferate in vitro following a new MOG challenge, an observation suggesting that a state of peripheral tolerance was produced by the MSCs. In a subsequent publication, Zhang and colleagues administered IV xenogeneic (human) MSCs to EAE-affected mice and observed clinical improvement as well as improvement of histological scores and some evidence of oligodendrogenesis, possibly through the release of neurotrophic factor 38]. In 2006 Zhang et co. confirmed that MSCs administration protected neurons from the EAE-associated inflammatory attack. They also observed a small degree of co-localization (less than $10 \%$ at best) of labeled human MSCs with cells expressing neural markers 39]. Their observations, therefore, suggested that some transdifferentiation had occurred.

\section{Migratory features of MSCs and "homing"}

There are numerous in vitro and in vivo studies showing the potential of MSCs to migrate and engraft after intravenous administration or brain transplantation and the ability to survive in the microenvironment of nervous tissue. In healthy animals the majority of transplanted MSCs trafficked to lymph nodes, lungs and spleen but in EAE animal models MSCs are attracted to sites of lesion. Similar to immune cells, MSCs can extravasate from the blood vessels as a result of the expression of adhesion molecules on their surface. MSCs show coordinated rolling and adhesion behaviour on endothelial cells in a p-selectin- and vascular celladhesion molecule 1 (VCAM1)-dependent manner 40].

MSCs migrate in response to several chemokines that bind to cognate receptors expressed on their cell surface 41 and lead to the activation of matrix metalloproteinases that degrade the basement membrane and allow subsequent extravasation 42].

The experiments of Jackson and coworkers showed that systemically administered MSCs seem to preferentially home to the site of injury, where they support functional recovery 43].

Tyukavin and colleagues showed that activation of apoptosis is a potent physiological stimulus for targeted migration of MSCs from the blood to tissues 44].

Karp M and Leng Teo GS (2009) 45 . discussed in 
their review the issues regarding tracking and efficacy of homing to the inflammation sites in CNS for exogenously delivered MSCs and also if host MSCs can be mobilized into peripheral blood and then target the lesions.

He Q. and coworkers $46 . \quad$ reviewed the studies about peripheral blood MSCs and the factors and conditions that promote their mobilization into the peripheral blood.

Taken together, these studies suggest that the clinical and pathological benefit appeared to be mediated by inhibition of peripheral encephalitogenic T-cells. However, several lines of evidence from animal studies suggest the beneficial effects of MSCs in EAE also may reflect a more direct influence of MSCs on neural cell responses to inflammatory CNS injury 47].

\section{Paracrine effect conducive of neuroprotection and neuroregeneration}

It has been showed on animal models of EAE that exogenous MSCs induce enhancement of endogenous repair processes through a "bystander activation" mechanism mediated by the production of multiple growth factors.

The secretion of varied neurotrophic factors such as: brain-derived neurotrophic factors (BDNF) 48], nerve growth factor (NGF) 49], insulin-like growth factor-1 (IGF-1) 50], glial derived neurotrophic factor (GDNF) 51.

is responsible for the neuroprotective effects and for neuroregeneration.

Through the release of trophic and anti-apoptotic molecules, MSCs rescues neurons and oligodendrocytes from apoptosis and can have anti-inflammatory and anti-proliferative effects on microglial cells and astrocytes, thus creating a neuroprotective microenvironment.

In addition, MSCs can promote the proliferation and maturation of local neural precursor cells, leading to their differentiation into mature neurons and oligodendrocytes.

MSC initiates the same endogenous repair through the same "by-stander activation" mechanism, as they induce proliferation, maturation and differentiation of neuronal local precursors into mature neurons, thus leading to a certain degree of neuronogenesis.

MSCs migrate into the CNS where they promote BDNF production and induce proliferation of a limited number of oligodendrocyte progenitors in oligodendrocytes, helping oligodendrogenesis, which enhances remyelination and improves axonal integrity in lesions 52].

\section{Neuronal differentiation}

Studies were carried out involving cancer patients who received intravenous injection of bromodeoxyuridine in order to map out the neuronal division. In these patients CNS was studied after death and the findings are that new neurons are continuously generated 53]. It is the current view that, under normal condition, stem cells from a normal brain can permanently renew themselves and have a pluripotent capacity to differentiate into many cells 54-57]. Although the human brain stem cells are capable capacity of continuous renewal, it is not known why these cells show reduced ability to proliferate and differentiate into neurons when it is necessary to repair a CNS injury.

In order to recognize MSC differentiation into neuron-like cells certain morphologic parameters and phenotypic changes need to be evaluated 58-61].

Some studies described MSC differentiation into cells with extensions similar to neuronal extesions hours after treating MSC with certain chemical substances 62], while other studies reported MSC transdifferentiation into neuronal phenotypes or functional neurons which had functional synaptic transmission, in the context of a specific induction 63]. Zeng and and his coworkers $64 . \quad$ studied the BM-MSC capacity to differentiate into neuron-like cells in vitro, in various conditions and concluded that these cells have great potential to differentiate into functional neurons. The presence of VEGF, BDNF or of $2 \%$ dimethyl sulfoxide in MSC culture can stimulate these cells to develop neuronal morphology and to start expressing neuronal markers 65,66 . However, it remains unclear whether this phenomenon reflects transdifferentiation, ectopic expression of markers or cell fusion. In studies with labeled MSC limited data were obtained concerning the transformation of transplanted MSC into functional neuronal cells.

There is much controversy in the scientific community regarding the neuronal differentiation of MSC. The reasons are as follows:

1. the ability of MSC to differentiate into cells of all three germ layers must be carefully considered because there are studies that reported the ability of MSC to express spontaneous neuronal markers, even in the undifferentiated state. If we assume that there is neuronal differentiation, it is not clear what factors determine the molecular profile of MSC differentiation after transplantation.

2. neuron-like cells in which MSC differentiate are not functional neurons, but cells with pseudo- 
neuronal morphology caused by chemical induction 67-70].

3. there is no correlation between the number of MSC and functional recovery, which means that neurological recovery can be determined not by the differentiation of MSC, but by the mediators secreted by MSC which limit cell death and stimulate the proliferation of progenitor cells 71,72].

4. MSC differentiation into neuronal phenotypes was mainly the result of the donor MSC merging with the host cells, which led to the false immunopositive results at characterization time 73].

\section{Angiogenesis}

Research has shown that MSCs from bone marrow are able to remodel vascularization by increasing the synthesis of numerous cytokines, including IL-6, IL-7 and VEGF 74-79].

\section{Axonal sprouting}

MSC provides a conducive environment for axonal regeneration, axonal guidance, neuronal cells migration, degradation of glial scars through matrix metalloproteinases (MMPs) and bypasses lesions by synthesis of certain matrix components permissive for neurons inside the lesions, which helps reduce cavitation in the damaged tissue and raises the possibility of interneuronal interaction 26,80-83].

\section{Experimental studies and clinical experience with mesenchymal stem cell therapy}

Clinical experience with mesenchymal stem cell therapy is represented by pilot studies, open-labeled studies, several non-randomized studies and randomized studies.

In a recent paper, Karussis and his colleagues 84 . conducted an analysis and synthesis of these studies and highlighted the following: the allogeneic transplant using stem cells from donor seems to have a higher potential to achieve neural repair, because the transplanted stem cells do not have the genetic defects involved in the pathogenesis of the neurological disease. Donor stem cells can also operate as the vehicle for transfer of normal gene in neurogenetic syndromes. Apart from some small studies which used MSC from bone marrow, the literature data are very limited in terms of allogeneic transplantation. In a pioneering study 85 . in which allogeneic MSC infusion was used in patients with Hurler syndrome (mucopolysaccharidosis type $\mathrm{IH}$ ) or metachromatic leukodystrophy, no toxic effects were found and, although the clinical state of the patients was stable, an improvement in the nerve conduction velocity was recorded.

The main disadvantage of allogeneic transplantation is the risk of rejection of transplanted 86 . cells and the potential need for immunosuppressive therapy in order to improve the cells' long-term viability. This problem seems to be less striking in embryonic stem cells because these type of cells seem to be immuneprivileged 87,88 ]. Most clinical data result from clinical trials involving autologous stem cells.

A clinical research study with MSC recorded on www.clinicaltrial.gov highlights a number of 310 clinical trials out of which 48 for neurological diseases: multiple sclerosis, amyotrophic lateral sclerosis, Parkinson's disease, cerebellar ataxia, brain stroke, head and spinal trauma, Duchenne muscular dystrophy and other diseases.

A systematic review and meta-analysis of clinical trials with MSC 89. including 36 studies and 1012 participants did not detect an association between acute infusional toxicity, organ system complications, infection, death or malignancy. However there was a significant association between MSC and transient fever. Based on the current clinical trials, MSC therapy appears safe, still further larger scale controlled clinical trials with rigurous reporting adverse events are required to further define the safety profile of MSC.

\section{REFERENCES}

1. Thomson JA, Itskovitz-Eldor J, Shapiro SS,WaknitzMA, Swiergiel JJ,Marshall VS, et al. Embryonic stemcell lines derived from human blastocysts. Science 1998;282:1145-7.

2. Ben-David U, Benvenisty N. The tumorigenicity of human embryonic and induced pluripotent stem cells. Nat Rev Cancer 2011;11:268-77.

3. Gage FH. Mammalian neural stem cells. Science 2000;287:1433-8.

4. Jiang $Y$, Jahagirdar BN, Reinhardt RL, Schwartz RE, Keene CD, OrtizGonzalez XR, et al. Pluripotency of mesenchymal stem cells derived from adult marrow. Nature 2002;418:41-9.

5. Mathews DJ, Sugarman J, Bok H, Blass DM, Coyle JT, Duggan P, et al. Cell-based interventions for neurologic conditions: ethical challenges for early human trials. Neurology 2008;71:288-93.

6. Dominici, M., Le Blanc, K., Mueller, I., Slaper-Cortenbach, I., Marini, F., Krause, D., Deans, R., Keating, A., Prockop, D., Horwitz, E., 2006. Minimal criteria for defining multipotent mesenchymal stromal cells. The International Society for Cellular Therapy position statement. Cytotherapy 8, 315-317.

7. Friedenstein, A.J., et al., Stromal cells responsible for transferring the microenvironment of the hemopoietic tissues. Cloning in vitro and retransplantation in vivo. Transplantation, 1974. 17(4): p. 331-40.

8. Pedemonte $\mathrm{E}$., et al., The molecular signature of therapeutic mesenchymal stem cells exposes the architecture of the hematopoietic stem cell niche synapse. BMC Genomics, 2007. 8: p. 65

9. Uccelli A, Moretta L, Pistoia V. Mesenchymal stem cells in health and disease. Nat Rev Immunol 2008; 8(9): 726-736.

10. Prockop DJ. Marrow stromal cells as stem cells for nonhematopoietic tissues. Science 1997;276:71-4.

11. Dimitrios Karussis, Ibrahim Kassis, Basan Gowda S. Kurkalli, Shimon 
Slavin. Immunomodulation and neuroprotection with mesenchymal bone marrow stem cells (MSCs): A proposed treatment for multiple sclerosis and other neuroimmunological/neurodegenerative diseases. Journal of the Neurological Sciences 265 (2008) 131-135.

12. Mesenchymal stem cells for the treatment of multiple sclerosis and othe neurological diseases Antonio Uccelli, Alice Laroni, Mark S Freedman. Lancet Neurol 2011; 10: 649-56

13. Karussis D, Kassis I, Kurkalli BGS, Slavin S. Immunomodulation and neuroprotection with mesenchymal bone marrow stem cells (MSCs): A proposed treatment for multiple sclerosis and other neuroimmunological /neurodegenerative diseases. J NeurolSci 2008; 265: 131-135.

14. Keating A. Mesenchymal stromal cells. Curr Opin Hematol 2006; 13(6): 419-425

15. Uccelli A, Moretta L, Pistoia V. Mesenchymal stem cells in health and disease. Nature Rev Immunol 2008; 8: 726-736.

16. Krampera M, Pasini A, Pizzolo G, Cosmi L, Romagnani S, Annunziato F Regenerative and immunomodulatory potential of mesenchymal stem cells. Curr Opin Pharmacol 2006;6:435-41

17. Le Blanc K, Tammik L, Sundberg B, Haynesworth SE, Ringden 0 . Mesenchymal stem cells inhibit and stimulate mixed lymphocyte cultures and mitogenic responses independently of the major histocompatibility complex. Scand J Immunol 2003;57:11-20.

18. JacksonJS, Golding JP, Chapon C, Jones WA, Bhakoo KKJackson et al. Homing of stem cells to sites of inflammatory brain injury after intracerebra and intravenous administration: a longitudinal imaging study. Stem Cell Research \& Therapy 2010, 1:17

19. Karp JM, Sock Leng Teo G. Mesenchymal Stem Cell Homing: The Devil Is in the Details. Cell Stem Cell 4, March 6, 2009, 206-216

20. He, Q., Wan, C., and Li, G. (2007). Concise review: multipotent mesenchymal stromal cells in blood. Stem Cells 25, 69-77.

21. Hongqi Xin, Yi Li, Ben Buller, Mark Katakowski, Yi Zhang, Xinli Wang, Xia Shang, Zheng Gang Zhang, Michael Chopp. Exosome-Mediated Transfer of miR-133b from Multipotent Mesenchymal Stromal Cells to Neural Cells Contributes to Neurite Outgrowth. Stem Cells, vol 30 issue 7 1556-1564, 2012

22. Jiang, X. X. et al. Human mesenchymal stem cells inhibit differentiation and function of monocyte derived dendritic cells. Blood 105, 4120-4126 (2005).

23. Nauta, A. J., Kruisselbrink, A. B., Lurvink, E., Willemze, R. \& Fibbe, W. E. Mesenchymal stem cells inhibit generation and function of both CD34+derived and monocyte-derived dendritic cells. J. Immunol. 177, 2080-2087 (2006).

24. Ramasamy, R. et al. Mesenchymal stem cells inhibit dendritic cell differentiation and function by preventing entry into the cell cycle. Transplantation $83,71-76(2007)$

25. Li, Y. P. et al. Human mesenchymal stem cells license adult CD34+ hemopoietic progenitor cells to differentiate into regulatory dendritic cells through activation of the Notch pathway. J. Immunol. 180, 1598-1608 (2008)

26. Aggarwal, S. \& Pittenger, M. F. Human mesenchymal stem cells modulate allogeneic immune cell responses. Blood 105, 1815-1822 (2005).

27. Beyth, S. et al. Human mesenchymal stem cells alter antigen-presenting cell maturation and induce T-cell unresponsiveness. Blood 105 2214-2219 (2005).

28. Maccario, R. et al. Interaction of human mesenchymal stem cells with cells involved in alloantigen-specific immune response favors the differentiation of CD4+ T-cell subsets expressing a regulatory/suppressive phenotype. Haematologica 90, 516-525 (2005)

29. Spaggiari, G. M., Capobianco, A., Becchetti, S., Mingari, M. C. \& Moretta, L. Mesenchymal stem cell- natural killer cell interactions: evidence that activated NK cells are capable of killing MSCs, whereas MSCs can inhibit IL-2-induced NK-cell proliferation. Blood 107, 1484-1490 (2006).

30. Glennie, S., Soeiro, I., Dyson, P. J., Lam, E. W. \&Dazzi, F. Bone marrow mesenchymal stem cells induce division arrest anergy of activated T cells. Blood 105, 2821-2827 (2005).

31. Augello, A. et al. Bone marrow mesenchymal progenitor cells inhibit lymphocyte proliferation by activation of the programmed death 1 pathway. Eur. J. Immunol. 35, 1482-1490 (2005)

32. Corcione, A. et al. Human mesenchymal stem cells modulate B-cell functions. Blood 107, 367-372 (2006).

33. Zappia E, Casazza S, Pedemonte E, Benvenuto F, Bonanni I, Gerdoni E, et al. Mesenchymal stem cells ameliorate experimental autoimmune encephalomyelitis inducing T-cell anergy. Blood 2005;106:1755-61

34. Krampera M, Pasini A, Pizzolo G, Cosmi L, Romagnani S, Annunziato F. Regenerative and immunomodulatory potential of mesenchymal stem cells. Curr Opin Pharmacol 2006;6:435-41.

35. Le Blanc K, Tammik L, Sundberg B, Haynesworth SE, Ringden 0. Mesenchymal stem cells inhibit and stimulate mixed lymphocyte cultures and mitogenic responses independently of the major histocompatibility complex. Scand J Immunol 2003;57:11-20.

36. Beyth S, Borovsky Z, Mevorach D, Liebergall M, Gazit Z, Aslan H, et al. Human mesenchymal stem cells alter antigen-presenting cell maturation and induce T-cell unresponsiveness. Blood 2005;105: 2214-9

37. Spaggiari GM, Capobianco A, Becchetti S, Mingari MC, Moretta L. Mesenchymal stem cell-natural killer cell interactions: evidence that activated NK cells are capable of killing MSCs, whereas MSCs can inhibit IL-2-induced NK-cell proliferation. Blood 2006;107: 1484-90

38. Zhang J, Li Y, Chen J, Cui Y, Lu M, Elias SB, et al. Human bone marrow stromal cell treatment improves neurological functional recovery in EAE mice. Exp Neurol 2005;195:16-26.

39. Zhang, J., et al., Bone marrow stromal cells reduce axonal loss in experimental autoimmune encephalomyelitis mice. J Neurosci Res, 2006. 84(3): p. 587-95.

40. Ruster, B. et al. Mesenchymal stem cells display coordinated rolling and adhesion behavior on endothelial cells. Blood 108, 3938-3944 (2006).

41. Sordi, V. et al. Bone marrow mesenchymal stem cells express a restricted set of functionally active chemokine receptors capable of promoting migration to pancreatic islets. Blood 106, 419-427 (2005).

42. Son, B. R. et al. Migration of bone marrow and cord blood mesenchymal stem cells in vitro is regulated by stromal-derived factor-1-CXCR4 and hepatocyte growth factor-c-Met axes and involves matrix metalloproteinases. Stem Cells 24, 1254-1264 (2006).

43. Jackson JS, Golding JP, ChaponC, Jones WA, Bhakoo KK et al. Homing of stem cells to sites of inflammatory brain injury after intracerebral and intravenous administration: a longitudinal imaging study. Stem Cell Research \& Therapy 2010, 1:17

44. A. I. Tyukavin, M. M. Galagudza, V. M. Mikhailov, A. A. Venkov, G. Sh. Mchedlidze, N. V. Burkova. Mechanism of Targeted Migration of Mesenchymal Stem CellsCell Technologies in Biology and Medicine, №. 2 , August, 2012, p577-580.

45. Karp JM, Sock Leng Teo G. Mesenchymal Stem Cell Homing: The Devil Is in the Details Cell Stem Cell 4, March 6, 2009, 206-216

46. He, Q., Wan, C., and Li, G. (2007). Concise review: multipotent mesenchymal stromal cells in blood. Stem Cells 25, 69-77

47. Einstein O, Fainstein N, Vaknin I, Mizrachi-Kol R, Reinhartz E, Grigoriadis N, et al. Neural precursors attenuate autoimmune encephalomyelitis by peripheral immunosuppression. Ann Neurol 2007;61:209-18

48. Wilkins, A., Kemp, K., Ginty, M., Hares, K., Mallam, E., Scolding, N., 2009. Human bone marrow-derived mesenchymal stem cells secrete brainderived neurotrophic factor which promotes neuronal survival in vitro. Stem Cell Res.

49. Choi, M.R., Kim, H.Y., Park, J.Y., Lee, T.Y., Baik, C.S., Chai, Y.G., Jung, K.H., Park, K.S., Roh, W., Kim, K.S., Kim, S.H., 2010. Selection of optimal passage of bone marrow-derived mesenchymal stem cells for stem cell therapy in patients with amyotrophic lateral sclerosis. Neurosci. Lett. 472, 94-98.

50. Wakabayashi, K., Nagai, A., Sheikh, A.M., Shiota, Y., Narantuya, D., Watanabe, T., Masuda, J., Kobayashi, S., Kim, S.U., Yamaguchi, S., 2010. Transplantation of human mesenchymal stem cells promotes functional improvement and increased expression of neurotrophic factors in a rat focal cerebral ischemia model. J. Neurosci. Res. 88, 1017-1025.

51. Whone, A.L., Kempa, K., Suna, M., Wilkinsa, A., Scolding, N.J., 2012. Brain Research 1431, 86-96. Human bone marrow mesenchymal stem cells protect catecholaminergic and serotonergic neuronal perikarya and transporter function from oxidative stress by the secretion of glial-derived neurotrophic factor

52. Crigler L, Robey RC, Asawachaicharn A, Gaupp D, Phinney DG: Human mesenchymal stem cell subpopulations express a variety of neuro-regulatory molecules and promote neuronal cell survival and neuritogenesis. Experimental neurology 198:54- 64, 2006

53. Eriksson PS, Perfilieva E, Bjork-Eriksson T, Alborn AM, Nordborg C, Peterson DA, Gage FH: Neurogenesis in the adult human hippocampus. Nat 
Med 4:1313-1317, 1998

54. Brustle $\mathrm{O}$, Jones KN, Learish RD, Karram K, Choudhary K, Wiestler OD, Duncan ID, McKay RD: Embryonic stem cell-derived glial precursors: a source of myelinating transplants. Science 285:754-756, 1999

55. Flax JD, Aurora S, Yang C, Simonin C, Wills AM, Billinghurst LL, Jendoubi M, Sidman RL, Wolfe JH, Kim SU, Snyder EY: Engraftable human neural stem cells respond to development cues, replace neurons, and express foreign genes. Nat Biotech 16:1033- 1039, 1998.

56. Kim S: Human neural stem cells genetically modified for brain repair in neurological disorders. Neuropathology 24:159-174, 2004

57. San DWY, Ray J, Gage FH: Bipotent progenitor cell lines from the human CNS. Nat Biotech 15:574-580, 1997.

58. Dezawa M, Kanno H, Hoshino M, Cho H, Matsumoto N, Itokazu Y, Tajima N, Yamada H, Sawada H, Ishikawa H, Mimura T, Kitada M, Suzuki Y, Ide C: Specific induction of neuronal cells from bone marrow stromal cells and application for autologous transplantation. J Clin Invest 113:1701-1710, 2004

59. Hofstetter CP, Schwarz EJ, Hess D, Widenfalk J, El Manira A, Prockop DJ Olson L: Marrow stromal cells form guiding strands in the injured spinal cord and promote recovery. Proc Natl Acad Sci U S A 99:2199-2204, 2002

60. Jiang $Y$, Jahagirdar BN, Reinhardt RL, Schwartz RE, Keene CD, OrtizGonzalez XR, Reyes M, Lenvik T, Lund T, Blackstad M, Du J, Aldrich S, Lisberg A, Low WC, Largaespada DA, Verfaillie CM: Pluripotency of mesenchymal stem cells derived from adult marrow. Nature 418:41-49, 2002.

61. Qian L, Saltzman WM: Improving the expansion and neuronal differentiation of mesenchymal stem cells through culture surface modification. Biomaterials 25:1331-1337, 2004.

62. Alexanian AR, Fehlings MG, Zhang Z, Maiman DJ: Transplanted neurally modified bone marrow-derived mesenchymal stem cells promote tissue protection and locomotor recovery in spinal cord injured rats. Neurorehabil Neural Repair 25:873-880, 2011.

63. Naghdi M, Tiraihi T, Namin SA, Arabkheradmand J: Transdifferentiation of bone marrow stromal cells into cholinergic neuronal phenotype: a potential source for cell therapy in spinal cord injury. Cytotherapy 11:137-152, 2009

64. Zeng R, Wang L-W, Hu Z-B, Guo W-T, Wei J-S, Lin H, Sun X, Chen L-X Yang L-J: Differentiation of Human Bone Marrow Mesenchymal Stem Cells into Neuron-Like Cells In Vitro. Spine 36:997-1005, 2011.

65. Sanchez-Ramos J, Song S, Cardozo-Pelaez F, Hazzi C, Stedeford T, Willing A, Freeman TB, Saporta S, Janssen W, Patel N, Cooper DR, Sanberg PR: Adult bone marrow stromal cells differentiate into neural cells in vitro. Exp Neurol 164:247-256, 2000

66. Woodbury D, Schwarz EJ, Prockop DJ, Black IB: Adult rat and human bone marrow stromal cells differentiate into neurons. Journal of neuroscience research 61:364-370, 2000.

67. Croft AP, Przyborski SA: Formation of neurons by non-neural adult stem cells: potential mechanism implicates an artifact of growth in culture. Stem Cells 24:1841-1851, 2006

68. Lu P, Blesch A, Tuszynski MH: Induction of bone marrow stromal cells to neurons: differentiation, transdifferentiation, or artifact? J Neurosci Res 77:174-191, 2004

69. Neuhuber B, Gallo G, Howard L, Kostura L, Mackay A, Fischer I: Reevaluation of in vitro differentiation protocols for bone marrow stromal cells: disruption of actin cytoskeleton induces rapid morphological changes and mimics neuronal phenotype. J Neurosci Res 77:192-204, 2004.

70. Vallieres L, Sawchenko PE: Bone marrow-derived cells that populate the adult mouse brain preserve their hematopoietic identity. J Neurosci 23:5197-5207, 2003

71. Mahmood A, Lu D, Chopp M: Marrow Stromal Cell Transplantation after Traumatic Brain Injury Promotes Cellular Proliferation within the Brain. Neurosurgery 55:1185-1193, 2004.
72. Wei X, Du Z, Zhao L, Feng D, Wei G, He Y, Tan J, Lee WH, Hampel H, Dodel R, Johnstone BH, March KL, Farlow MR, Du Y: IFATS collection: The conditioned media of adipose stromal cells protect against hypoxiaischemia-induced brain damage in neonatal rats. Stem Cells 27:478-488, 2009

73. Weimann JM, Johansson CB, Trejo A, Blau HM: Stable reprogrammed heterokaryons form spontaneously in Purkinje neurons after bone marrow transplant. Nature cell biology 5:959-966, 2003.

74. Chen J, Zhang ZG, Li Y, Wang L, Xu YX, Gautam SC, Lu M, Zhu Z, Chopp $M$ : Intravenous administration of human bone marrow stromal cells induces angiogenesis in the ischemic boundary zone after stroke in rats. Circulation research 92:692-699, 2003

75. Krupinski J, Kaluza J, Kumar P, Kumar S, Wang JM: Role of angiogenesis in patients with cerebral ischemic stroke. Stroke; a journal of cerebral circulation 25:1794-1798, 1994

76. Onda T, Honmou O, Harada K, Houkin K, Hamada H, Kocsis JD: Therapeutic benefits by human mesenchymal stem cells (hMSCs) and Ang-1 gene-modified hMSCs after cerebral ischemia. Journal of cerebral blood flow and metabolism : official journal ofthe International Society of Cerebral Blood Flow and Metabolism 28:329-340, 2008

77. Toyama K, Honmou 0, Harada K, Suzuki J, Houkin K, Hamada H, Kocsis JD: Therapeutic benefits of angiogenetic gene-modified human mesenchymal stem cells after cerebral ischemia. Experimental neurology 216:47-55, 2009.

78. Ukai R, Honmou O, Harada K, Houkin K, Hamada H, Kocsis JD: Mesenchymal stem cells derived from peripheral blood protects against ischemia. Journal of neurotrauma 24:508-520, 2007

79. Zhukareva V, Obrocka M, Houle JD, Fischer I, Neuhuber B: Secretion profile of human bone marrow stromal cells: donor variability and response to inflammatory stimuli. Cytokine 50:317-321, 2010.

80. Ankeny DP, McTigue DM, Jakeman LB: Bone marrow transplants provide tissue protection and directional guidance for axons after contusive spinal cord injury in rats. Experimental neurology 190:17-31, 2004.

81. Hofstetter CP, Schwarz EJ, Hess D, Widenfalk J, El Manira A, Prockop DJ, Olson L: Marrow stromal cells form guiding strands in the injured spinal cord and promote recovery. Proc Natl Acad Sci U S A 99:2199-2204, 2002.

82. Neuhuber B, Timothy Himes B, Shumsky JS, Gallo G, Fischer I: Axon growth and recovery of function supported by human bone marrow stromal cells in the injured spinal cord exhibit donor variations. Brain research 1035:73-85, 2005

83. Phinney DG, Baddoo M, Dutreil M, Gaupp D, Lai WT, Isakova IA: Murine mesenchymal stem cells transplanted to the central nervous system of neonatal versus adult mice exhibit distinct engraftment kinetics and express receptors that guide neuronal cell migration. Stem cells and development 15:437-447, 2006

84. Karussis D, Petrou P, Kassis I. Clinical experience with stem cells and other cell therapies in neurological diseases. Journal of the Neurological Sciences 324 (2013) 1-9.

85. Koc ON, Day J, Nieder M, Gerson SL, Lazarus HM, Krivit W. Allogeneic mesenchymal stem cell infusion for treatment of metachromatic leukodystrophy (MLD) and Hurler syndrome (MPS-HH). Bone Marrow Transplant 2002;30:215-22

86. Eliopoulos N, Stagg J, Lejeune L, Pommey S, Galipeau J. Allogeneic marrow stromal cells are immune rejected by MHC class I- and class IImismatched recipient mice. Blood 2005;106:4057-65.

87. Li L, Baroja ML,Majumdar A, Chadwick K, Rouleau A, Gallacher L, et al. Human embryonic stem cells possess immune-privileged properties. Stem Cells 2004:22: 448-56.

88. Fandrich F, Dresske B, Bader M, Schulze M. Embryonic stem cells share immune-privileged features relevant for tolerance induction. J Mol Med 2002;80: 343-50. 